\title{
PENGGUNAAN REFORMULASI INOKULUM FUNGI MIKORIZA ARBUSKULA UNTUK JATI MUNA (Tectona grandis L.f.)
}

\author{
The utilization of inoculum reformulation of Arbuscular Mycorrhiza Fungi for Muna Teak
}

(Tectona grandis L.f.)

\author{
Asrianti Arif ${ }^{1}$, Irdika Mansur ${ }^{2}$, Sri Wilarso ${ }^{2}$ dan/and Dedy Duryadi ${ }^{3}$ \\ ${ }^{1)}$ Jurusan Kehutanan, Fakultas Pertanian, Universitas Haluoleo \\ Kampus Bumi Tridharma Anduonohu, Kendari Telp. (0401) 391929, Fax. (0401) 390496 \\ ${ }^{2)}$ Fakultas Kehutanan, Institut Pertanian Bogor, Kampus IPB Darmaga, Bogor \\ ${ }^{3)}$ Departemen Biologi, Fakultas FMIPA, Institut Pertanian Bogor
}

Naskah masuk : 19 Januari 2009; Naskah diterima : 13 Juli 2009

\begin{abstract}
The condition of marginal lands can be a limiting factor for the planting on tropical land. Therefore, it is important to have high quality seedling in order to be resistant and adaptive againts such condition. One of the alternatives that can be done is by using Arbuscular Mycorrhiza Fungi (AMF). Thus, inoculum reformulation of AMF is urgently done by adding materials that contain nutrient so as to speed up the response toward plant. so, this research is aimed at testing the result inoculum reformulation of AMF to increasing growth of Muna teak seedling, This experiment are factorial with randomized block design using two factor of treatment. First factor is inoculum reformulation of AMF, second factor is formulation dossage of AMF inoculum. Growth variable that observed were seedling height, seedling diametre, dry weight seedling, root-shoot ratio, infected root dry weight, roots colonisation and numbers of spore. The results showed that inoculum reformulation of AMF can increased the growth of Muna teak seedling. Glomus etunicatum with vermicompost $40 \%$ (A3) and Glomus sp. with vermicompost $40 \%$ (B3) inoculum treatment can result in an increase of dry weight seedling is 529\% and 500\%, respectively compared to control and the optimum dossage taken by inoculum reformulation $15 \mathrm{~g} / \mathrm{seedling}$ can increase the height and diametre of Muna teak. Roots colonisation variable correlating and give positive response for the growth of Muna teak seedling variable.
\end{abstract}

Key word: vermicompost, Muna teak, arbuscular mycorrhiza fungy (AMF)

\begin{abstract}
ABSTRAK
Kondisi lahan-lahan marginal dapat menjadi faktor pembatas bagi penanaman semai-semai tanaman kehutanan di lapangan. Dengan demikian perlu adanya penyiapan semai-semai yang berkualitas untuk dapat bertahan dan adaptif terhadap kondisi lapang. Salah satu alternatif yang dapat dilakukan adalah pemanfaatan Fungi Mikoriza Arbuskula (FMA). Reformulasi inokulum FMA perlu dilakukan dengan menambahkan bahan yang mengandung unsur hara dalam mempercepat responnya terhadap tanaman. Tujuan dari penelitian ini adalah untuk menguji hasil reformulasi inokulum FMA dalam meningkatkan pertumbuhan semai jati Muna (Tectona grandis L.f.). Penelitian ini menggunakan rancangan faktorial dalam rancangan acak kelompok (RAK), menggunakan 2 faktor perlakuan, faktor pertama yaitu reformulasi inokulum FMA dan faktor kedua adalah dosis inokulum. Peubah pertumbuhan yang diamati adalah tinggi semai $(\mathrm{cm})$, diameter batang $(\mathrm{cm})$, bobot kering semai $(\mathrm{g})$, nisbah pucuk akar, bobot kering akar terinfeksi (g), kolonisasi akar dan jumlah spora. Hasil penelitian menunjukkan bahwa perlakuan reformulasi inokulum FMA mampu meningkatkan pertumbuhan semai jati Muna. Perlakuan inokulum $G$. etunicatum dengan vermikompos $40 \%$ (A3) dan Glomus sp. dengan vermikompos $40 \%$ (B3) menghasilkan peningkatan bobot kering semai berturut-turut sebesar $529 \%$ dan 500\% dibanding kontrol dan pemberian dosis reformulasi inokulum FMA $15 \mathrm{~g} /$ semai merupakan dosis optimum yang dapat
\end{abstract}


meningkatkan tinggi dan diameter semai jati Muna. Peubah kolonisasi akar cenderung berkorelasi positif dengan peubah pertumbuhan semai jati Muna.

\section{Kata kunci: vermikompos, jati Muna, fungi mikoriza arbuskula (FMA)}

\section{PENDAhUluan}

Jati Muna (Tectona grandis L.f.) merupakan salah satu sumberdaya alam yang berpotensi dan perlu dijaga serta dipertahankan keberadaannya agar jangan sampai punah. Di Sulawesi Tenggara keberadaan jati Muna sangat memprihatinkan, mengingat luasan hutan produksi jati Muna sekarang sudah semakin berkurang dari 70.000 ha menjadi 1.000 ha (Menteri Kehutanan, 2005 dalam Husna, 2005), bahkan jati Malabar Muna hanya tersisa 13 tanaman dan 7 tunggul bertunas (Leksono, 2001 dalam Anonim, 2005). Penyebabnya antara lain eksploitasi kayu secara berlebihan dan illegal logging. Hal tersebut mengindikasikan perlunya progam rehabilitasi hutan guna mempertahankan populasi jati Muna.

Dalam upaya meningkatkan populasi jati Muna maka perlu dilakukan penanaman kembali. Pada lahan bekas penebangan jati tersebut akan menimbulkan kondisi lahan marjinal (defisiensi unsur hara dan pH masam) yang dapat menjadi kendala dalam merehabilitasi lahan tersebut. Kondisi lahan marjinal dapat menjadi faktor pembatas bagi penanaman semai-semai pohon kehutanan di lapangan. Dengan demikian perlu adanya penyiapan semai-semai yang berkualitas untuk dapat bertahan dan adaptif terhadap kondisi lapang. Salah satu alternatif yang dapat dilakukan adalah pemanfaatan fungi mikoriza arbuskula (FMA).

FMA merupakan salah satu agen hayati yang berasosiasi dengan akar tumbuhan hidup dan berperan dalam transfer hara (Brundrett, 2004). Peran FMA adalah membantu penyerapan unsur hara terutama hara $\mathrm{P}$ dan hara lain seperti $\mathrm{Zn}, \mathrm{Cu}, \mathrm{Ni} \mathrm{NH}_{4}^{+}$dan $\mathrm{NO}_{3}^{-}$, membantu penyediaan hara dari yang tidak tersedia menjadi tersedia bagi tanaman, membantu tanaman untuk dapat bertahan pada kondisi kekeringan karena adanya hifa-hifa cendawan yang mampu menembus pori-pori tanah dan memperluas daerah penyerapan air, dan sebagai proteksi dari serangan patogen akar (Brundrett et al., 1994; Smith dan Read, 1997).

Dalam rangka meningkatkan kualitas inokulum FMA, reformulasi inokulum dapat dilakukan yaitu dengan menambahkan bahan yang dapat menjadi unsur hara bagi tanaman. Penambahan bahan ini dapat meningkatkan pertumbuhan awal tanaman sebelum bersimbiosis dengan FMA dan lebih meningkatkan pertumbuhan setelah akar tanaman bersimbiosis dengan FMA. Salah satu bahan yang dapat ditambahkan adalah pupuk vermikompos. Vermikompos merupakan pupuk berkualitas tinggi sebab mengandung berbagai unsur hara seperti nitrogen, fosfor, kalium dan unsur-unsur mikro seperti sulfur, boron, dan zinc, juga mengandung berbagai hormon tumbuh bagi tanaman seperti auxin, sitokinin, giberellin (Nuryati, 2004), menyediakan energi untuk aktivitas mikroorganisme, meningkatkan porositas tanah, meningkatkan infiltrasi, kemampuan mengikat air, dan menurunkan pengaruh logam-logam berat (Samosir, 1994). Pemanfaatan vermikompos yang dikombinasikan dengan inokulum FMA kemudian dikemas dalam suatu bentuk reformulasi inokulum FMA baru yang tidak hanya mengandung propagul FMA akan tetapi juga mengandung residu vermikompos. Tujuan dari penelitian ini adalah untuk menguji hasil reformulasi inokulum FMA dalam meningkatkan pertumbuhan semai jati Muna.

\section{BAHAN DAN METODE}

\section{A. Waktu dan Tempat}

Penelitian ini dilaksanakan di rumah kaca Laboratorium Ekologi Hutan dan Laboratorium Silvikultur Fakultas Kehutanan IPB yang dilaksanakan selama 5 (lima) bulan dari bulan Maret sampai Juli 2006 . 


\section{B. Bahan dan Alat}

Bahan yang digunakan adalah tanaman inang Pueraria javanica, benih jati Muna, hasil reformulasi inokulum FMA jenis Glomus etunicatum dan Glomus sp. (endogenous) dengan vermikompos, tanah Latosol, $\mathrm{KOH} 25 \%, \mathrm{HCl} 2 \%(0,1 \mathrm{~N})$, trypan blue, asam laktat, gliserol, larutan Polyvinil Lactogliseryl (PVLG), larutan melzer, dan polybag.

Alat-alat yang digunakan adalah saringan spora $(63 \mu \mathrm{m}, 125 \mu \mathrm{m}, 250 \mu \mathrm{m}$, dan $500 \mu \mathrm{m})$, pinset spora, sentrifuse, timbangan analitik, oven, mikroskop binokuler Nikon YS100, mikroskop stereo binokuler Carton NSWT, mikroskop monookuler FCL 15 EX-N, kaca obyek dan gelas penutup.

\section{Metode}

\section{Persiapan Reformulasi Inokulum FMA}

Perbanyakan inokulum FMA jenis Glomus etunicatum dan Glomus sp. (endogenous) dilakukan dengan penambahan vermikompos sesuai perlakuan formulasi dan tanaman inang $P$. javanica. Pemeliharaan kultur dilakukan sampai berumur tiga bulan. Setelah tiga bulan dilakukan pengecekan untuk mengetahui pertumbuhan dan perkembangan spora dan dilakukan pengeringan untuk merangsang pembentukan spora lebih banyak. Hasil perbanyakan dikemas dalam bentuk inokulum baru yang dinamakan reformulasi inokulum FMA mengandung propagul FMA dan residu vermikompos.

\section{Persiapan benih jati Muna}

Perlakuan benih dilakukan berdasarkan metode Rizain (1999) yang dimodifikasi. Benih jati Muna direndam dalam air panas dengan suhu awal $80^{\circ} \mathrm{C}$ selama $24 \mathrm{jam}$, kemudian benih dijemur di bawah sinar matahari sepanjang hari dan malamnya direndam lagi dalam air dingin. Perlakuan tersebut diatas dilakukan selama 4 hari berturut-turut. Setelah itu dicampur dengan abu sekam yang dilembabkan dengan perbandingan 1:0,7:1 (benih : abu sekam : air) dan disimpan selama 24 jam. Kemudian benih siap disemaikan.

\section{Persiapan media perkecambahan dan media semai}

Media perkecambahan benih menggunakan pasir yang telah diayak kemudian dijemur di bawah sinar matahari. Media pasir ditempatkan pada bak-bak kecambah dengan ketebalan $10 \mathrm{~cm}$. Media tanam semai yang digunakan adalah pasir dan tanah jenis Latosol yang disterilkan kemudian dicampur dengan perbandingan (1:3). Media dimasukkan dalam polibag ukuran $20 \times 20 \mathrm{~cm}$ dengan berat media $2 \mathrm{~kg}$.

\section{Pengamatan Peubah Pertumbuhan}

Peubah pertumbuhan yang diamati dan diukur adalah tinggi semai yang diukur dari pangkal batang (pada satu titik yang tetap dekat permukaan tanah) sampai titik tumbuh tertinggi semai pada jalur batang dengan menggunakan mistar. Diameter batang diukur menggunakan jangka sorong pada ketinggian $1 \mathrm{~cm}$ dari permukaan tanah. Pengukuran dilakukan 2 minggu sekali, selain itu peubah lain yang diamati adalah bobot kering semai, bobot akar terinfeksi, nisbah pucuk akar, kolonisasi akar dan jumlah spora.

- Persentase akar yang dikolonisasi FMA dihitung berdasarkan rumus (Rajapakse dan Miller, 1992):

$$
\% \text { Kolonisasi FMA }=\frac{\text { Jumlah_bidang_pandang_yang_terkolonisasi_FMA }}{\text { Jumlah_total_bidang_pandang }} \times 100 \%
$$

- Menghitung jumlah spora pada akhir pengamatan, pemisahan spora dilakukan dengan metode tuang saring basah (Brundrett, 1994), dan dilakukan perhitungan spora di bawah mikroskop stereo binokuler Carton NSWT.

\section{Rancangan Penelitian}

Penelitian ini menggunakan rancangan faktorial dalam rancangan acak kelompok (RAK) menggunakan 2 faktor perlakuan, faktor pertama yaitu reformulasi inokulum FMA $(M)$ yang terdiri dari 
enam taraf yaitu formulasi G. etunicatum (A1), G. etunicatum dengan vermikompos $30 \%$ (A2), $G$. etunicatum dengan vermikompos $40 \%$ (A3), Glomus sp. (B1), Glomus sp. dengan vermikompos 30\% (B2), Glomus sp. dengan vermikompos 40\% (B3) dan kontrol. Faktor kedua adalah dosis inokulum FMA (D) yang terdiri dari tiga taraf yaitu $10 \mathrm{~g} / \mathrm{semai}(\mathrm{D} 1), 15 \mathrm{~g} / \mathrm{semai}$ (D2) dan $20 \mathrm{~g} / \mathrm{semai}$ (D3).

Adapun model statistik (Mattjik dan Sumertajaya, 2002) yang digunakan adalah :

$$
\boldsymbol{Y}_{i j k}=\boldsymbol{\mu}+\boldsymbol{M}_{i}+\boldsymbol{D}_{j}+(M D)_{i j}+\varlimsup_{k}+{ }_{i j k}
$$

Keterangan :

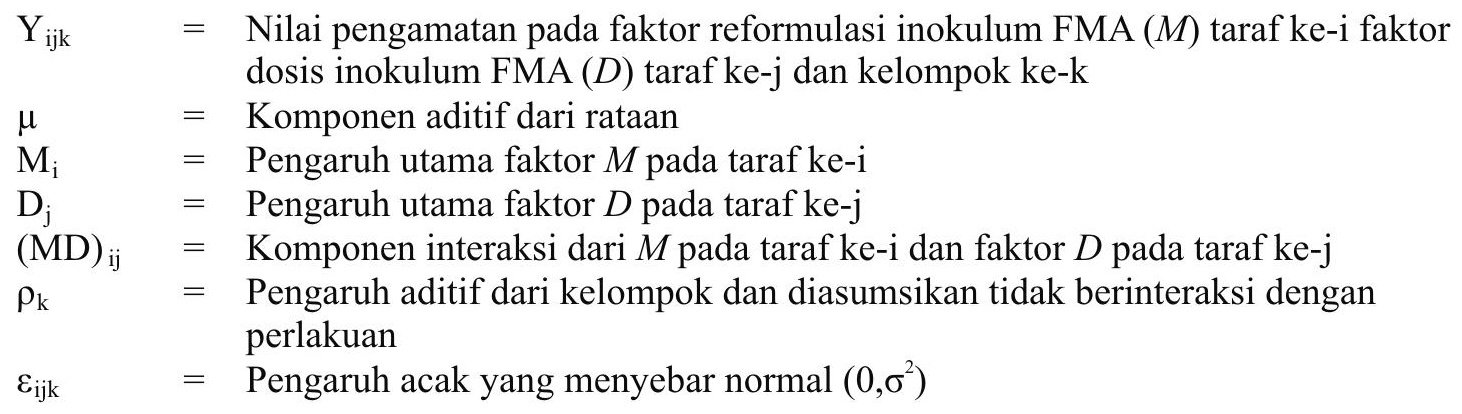

\section{E. Hipotesis}

Reformulasi inokulum FMA dengan vermikompos dapat meningkatkan pertumbuhan semai jati Muna di persemaian.

\section{F. Analisis Data}

Data hasil pengamatan dari masing-masing peubah dilakukan analisis ragam. Jika hasil analisis ragam menunjukkan F hitung $>$ dari F tabel maka dilanjutkan dengan uji Duncan pada taraf kepercayaan 95\% untuk membandingkan antar perlakuan (Mattjik dan Sumertajaya, 2002). Pengolahan data dilakukan dengan menggunakan progam komputer SAS V6.12 (Statistical Analysis System).

\section{HASIL DAN PEMBAHASAN}

\section{A. Hasil}

\section{Pertumbuhan semai jati Muna}

Perlakuan reformulasi inokulum FMA dan perlakuan dosis berpengaruh sangat nyata terhadap tinggi semai mulai minggu ke-6 dan diameter semai pada minggu ke-12, namun interaksi kedua perlakuan tersebut tidak nyata sampai pengukuran bulan ke tiga.

Grafik pertambahan tinggi semai jati Muna sampai pengukuran minggu ke-12 menunjukkan bahwa perlakuan reformulasi inokulum FMA cenderung memberikan respon yang lebih baik dibanding kontrol. Perlakuan reformulasi inokulum FMA jenis G. etunicatum dengan vermikompos $40 \%$ (A3) menghasilkan semai jati Muna tertinggi $(24,24 \mathrm{~cm})$ yang tidak berbeda nyata dengan reformulasi inokulum jenis Glomus sp. dengan vermikompos 40\% (B3) sebesar 22,41 cm (Gambar 1). 


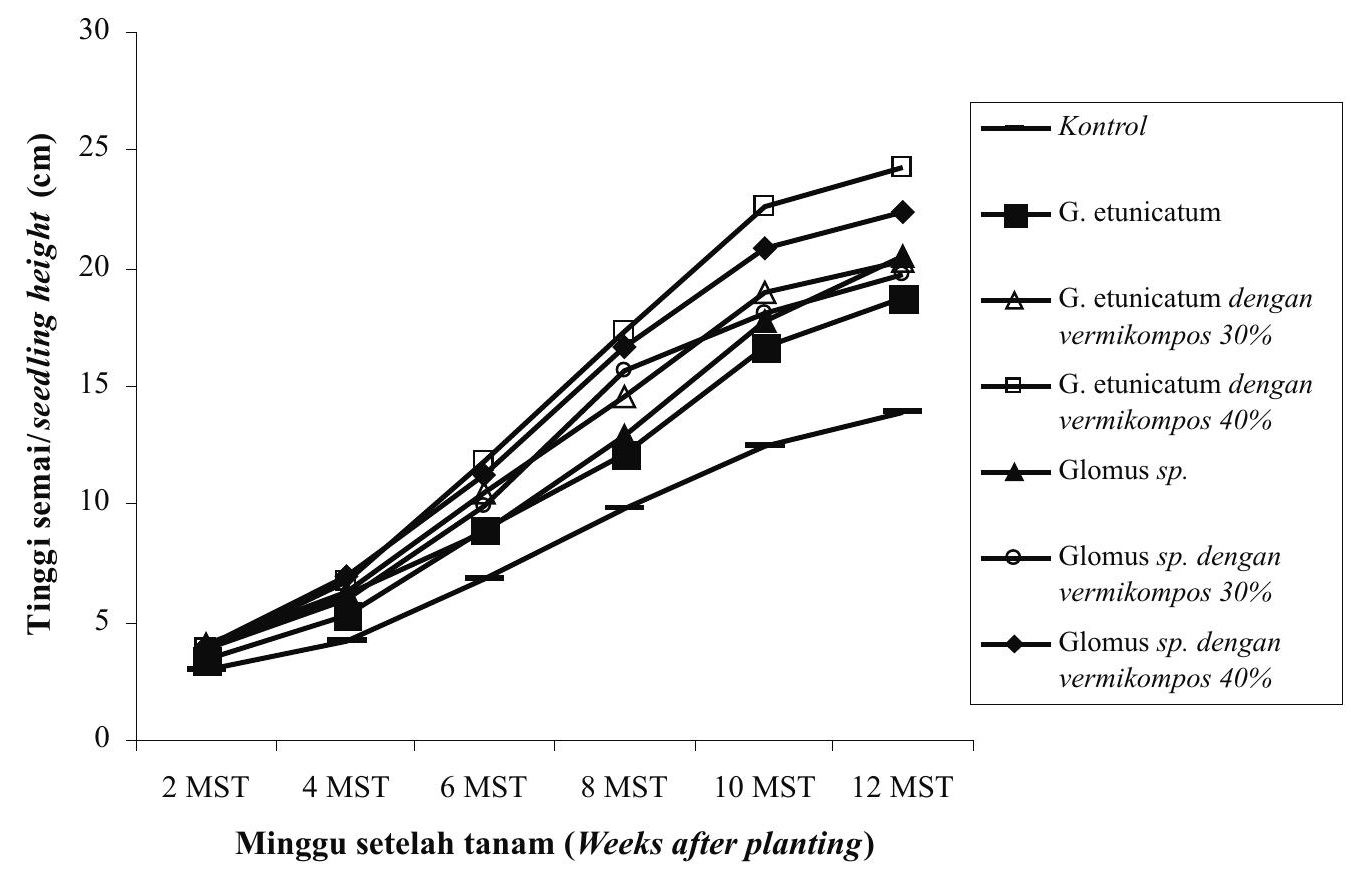

Gambar(Figure) 1. Pengaruh reformulasi inokulum FMA terhadap tinggi semai jati Muna sampai umur 12 MST di persemaian rumah kaca (The effect of inoculum reformulation of AMF on the height of Muna teak seedling 12 weeks after planting at the greenhouse)

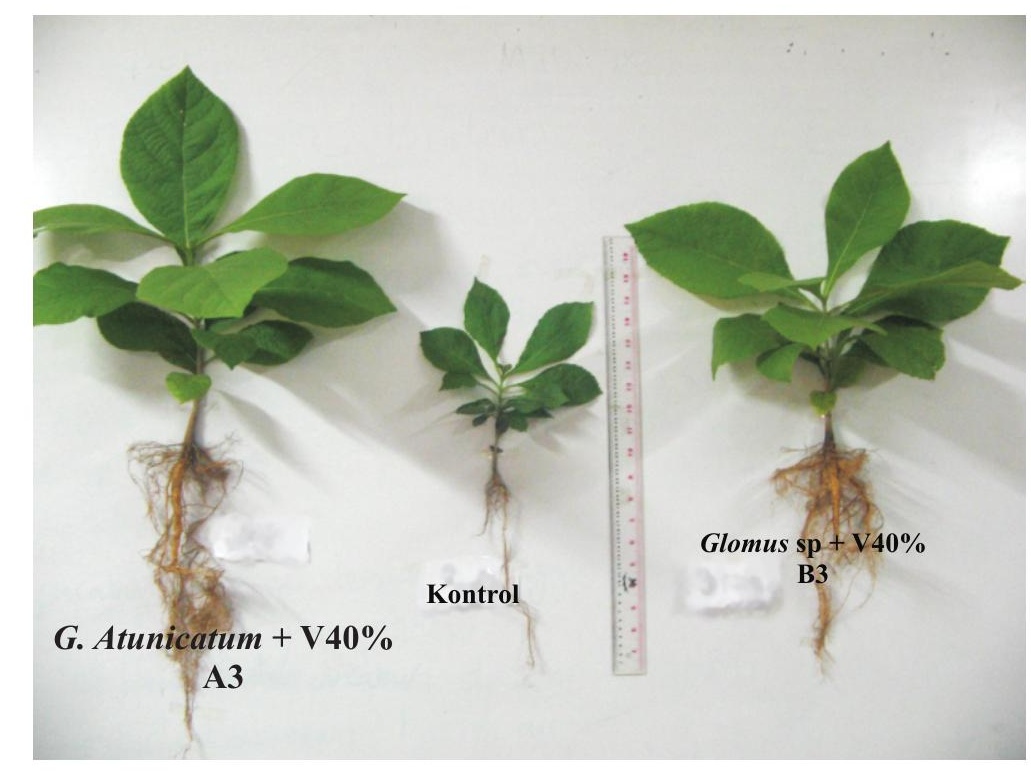

Gambar(Figure) 2. Semai jati Muna pada perlakuan reformulasi inokulum FMAA3 (kiri), perlakuan B3 (kanan) dan kontrol (tengah) pada umur 12 MST (Muna teak seedling innoculated inoculum reformulation of $A M F A 3$ (left), innoculated B3 (right) and control (middle) 12 weeks after planting) 
Perlakuan reformulasi inokulum FMA berpengaruh nyata terhadap diameter semai jati Muna pada umur 12 MST dan menghasilkan diameter yang lebih besar dibandingkan kontrol. Diameter semai tertinggi pada perlakuan $\mathrm{A} 3(0,77 \mathrm{~cm})$ tidak berbeda nyata dengan $\mathrm{B} 3(0,78 \mathrm{~cm})(\mathrm{Gambar} 3)$.

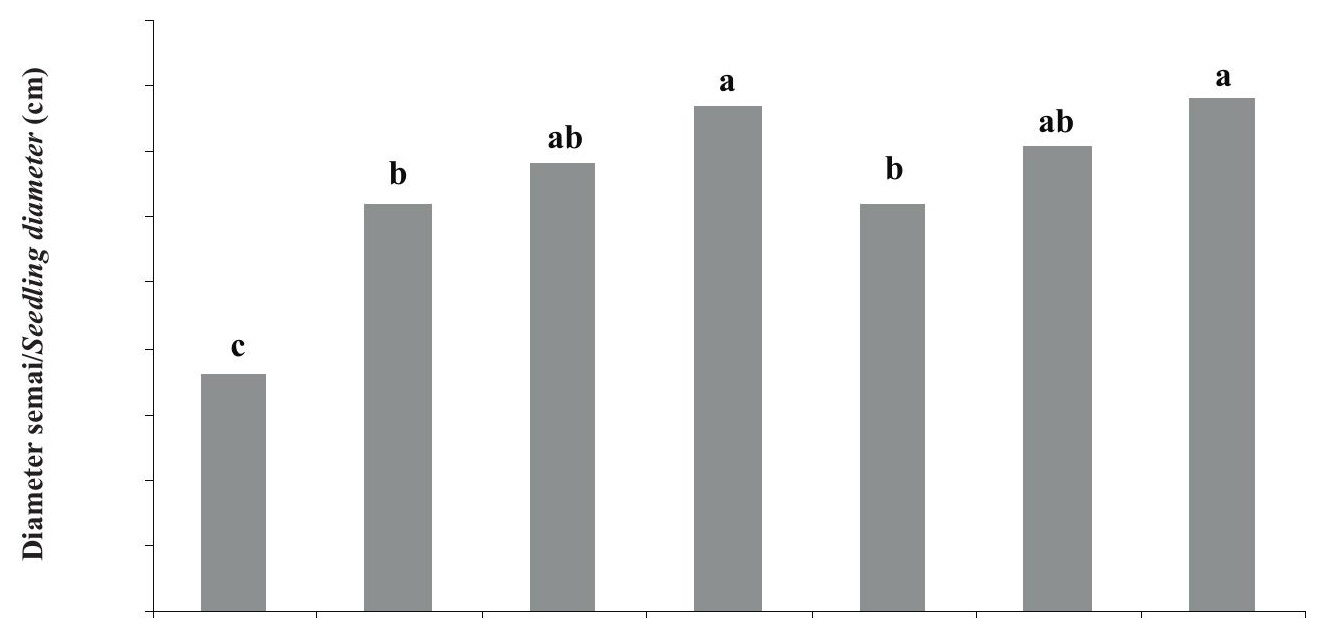

Perlakuan reformulasi FMA (Reformulation of AMF treatment)

Gambar(Figure) 3. Pengaruh reformulasi inokulum FMA terhadap diameter semai jati Muna 12 MST di persemaian rumah kaca (The effect of reformulation inoculum of AMF on the diametre of Muna teak seedling 12 weeks after planting at the greenhouse)

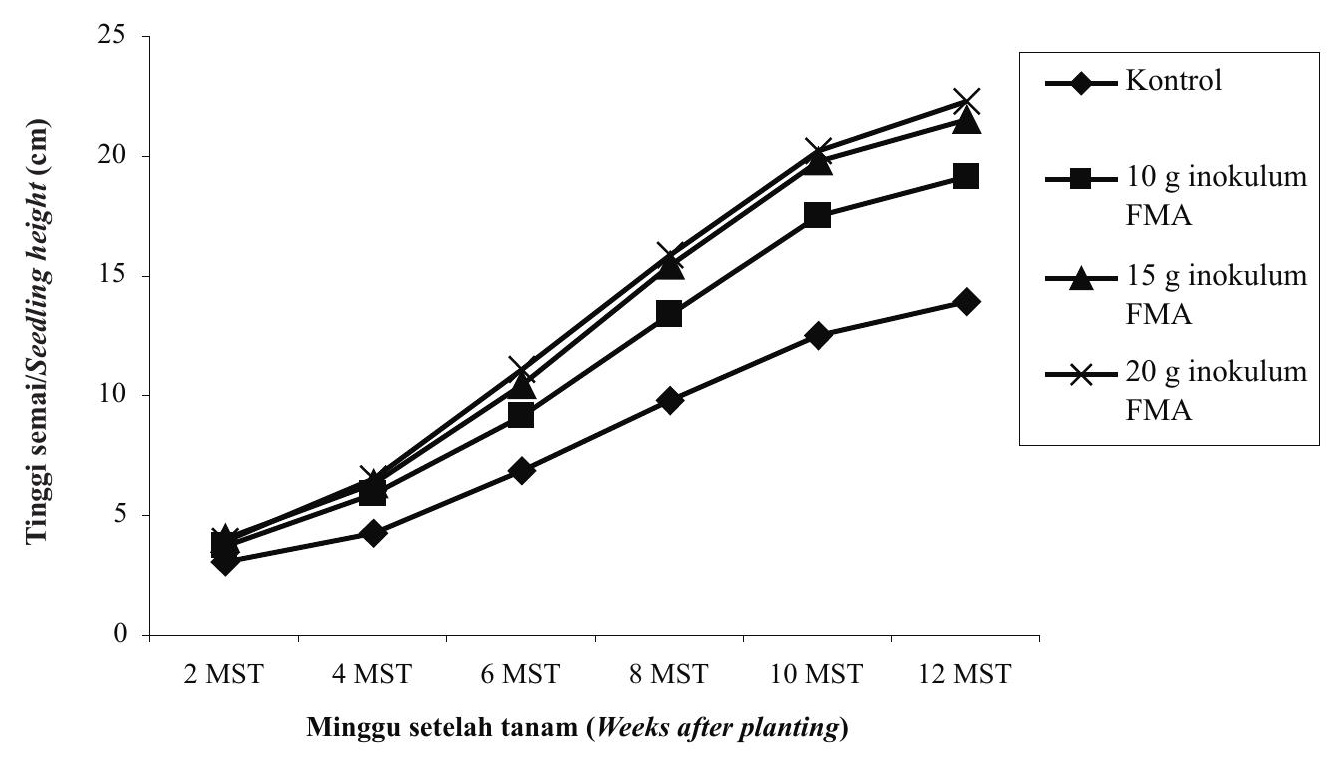

Gambar(Figure) 4. Pengaruh perlakuan dosis inokulum FMA terhadap tinggi semai jati Muna sampai umur 12 MST di persemaian rumah kaca (The effect of dosages inoculum of AMF treatment on the height of Muna teak seedling 12 weeks after planting at the greenhouse) 


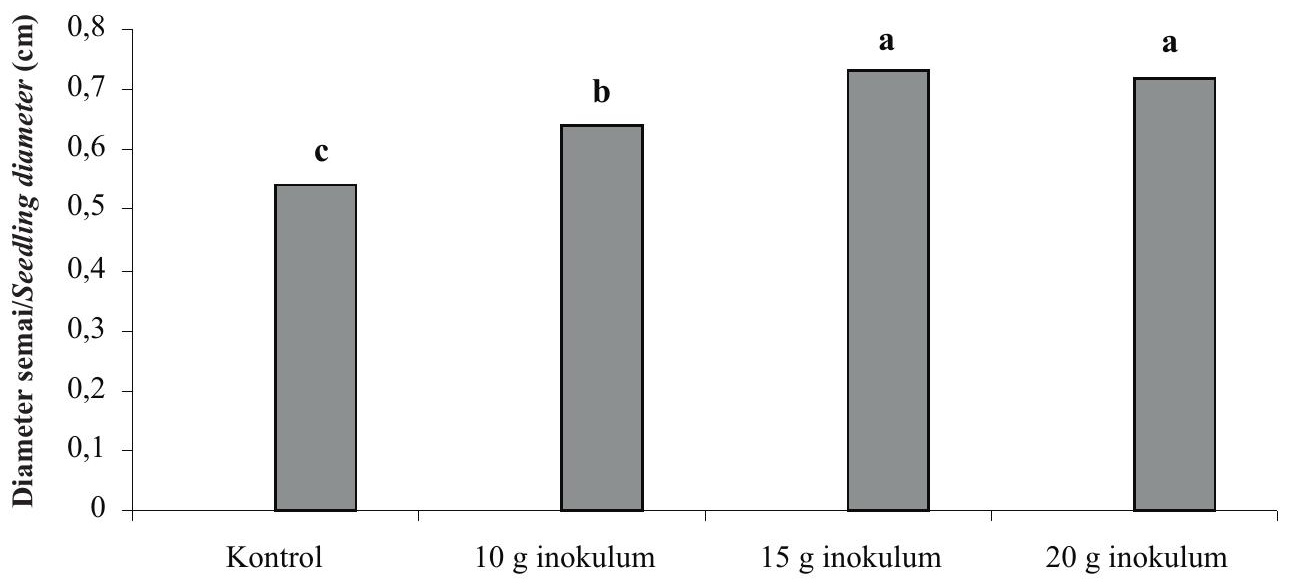

Perlakuan dosis inokulum FMA

(Treatment of the dosages of AMF inoculum )

Gambar(Figure) 5. Pengaruh perlakuan dosis inokulum FMA terhadap diameter semai jati Muna umur 12 MST di persemaian rumah kaca (The effect of inoculum dosages of AMF treatment on the diametre of Muna teak seedling 12 weeks after planting at the greenhouse)

Perlakuan dosis inokulum FMA juga berpengaruh nyata terhadap tinggi semai mulai minggu ke-6 dan diameter semai pada minggu ke-12. Pemberian reformulasi inokulum FMA sampai dosis $20 \mathrm{~g} / \mathrm{semai}$ secara nyata meningkatkan tinggi dan diameter semai, namun tidak berbeda nyata dengan dosis $15 \mathrm{~g} /$ semai (Gambar 4 dan 5). Hal ini mengindikasikan bahwa pemberian dosis $15 \mathrm{~g} / \mathrm{semai}$ sudah cukup untuk memenuhi kebutuhan unsur hara awal bagi semai jati Muna di persemaian.

Peningkatan bobot kering semai, nisbah pucuk akar, dan bobot kering akar terinfeksi secara nyata dipengaruhi oleh perlakuan reformulasi inokulum FMA. Bobot kering semai jati Muna yang diinokulasi dengan FMA meningkat dibandingkan dengan semai tanpa inokulasi FMA(kontrol). Perlakuan inokulum A3 dan B3 menghasilkan bobot kering semai dengan peningkatan berturut-turut sebesar 529\% dan 500\% dibanding kontrol. Sedangkan nilai NPA semai yang diinokulasi dengan inokulum FMA berkisar antara 1,20 sampai 2,07. Perlakuan reformulasi inokulum B2 menghasilkan nilai NPA terendah $(1,30)$ dan perlakuan kontrol menghasilkan nilai NPA tertinggi $(4,03)$. Perlakuan reformulasi inokulum A3 dan B3 juga menghasilkan bobot kering akar terinfeksi tertinggi dengan peningkatan berturut-turut $412 \%$ dan $419 \%$ dibanding kontrol (Tabel 1).

Tabel(Table) 1. Pengaruh reformulasi inokulum FMA terhadap bobot kering semai, nisbah pucuk akar dan bobot kering akar terinfeksi semai jati Muna (The effect of reformulation inoculum of AMF on the dry weight, root-shoot ratio, infected root dry weigh of Muna teak seedling)

\begin{tabular}{|c|cc|c|cc|cc|c|}
\hline $\begin{array}{c}\text { Perlakuan } \\
\text { (Treatment) }\end{array}$ & $\begin{array}{c}\text { Bobot kering } \\
\text { semai (g) } \\
\text { (Dry weight) }\end{array}$ & $\begin{array}{c}\text { Peningkatan } \\
\text { (Increased by) })\end{array}$ & $\begin{array}{c}\text { Nisbah } \\
\text { pucuk akar } \\
\text { (Root-shoot } \\
\text { ratio })\end{array}$ & $\begin{array}{c}\text { Bobot kering } \\
\text { akar terinfeksi } \\
\text { (Dry weight of } \\
\text { infected root })\end{array}$ & $\begin{array}{c}\text { Peningkatan } \\
\text { (Increased by) }\end{array}$ \\
\hline Kontrol & 2,26 & $\mathrm{~d}$ & 0 & 4,03 & $\mathrm{~d}$ & 0,41 & $\mathrm{c}$ & 0 \\
\hline $\mathrm{A} 1$ & 6,96 & $\mathrm{c}$ & $208 \%$ & 1,81 & $\mathrm{ab}$ & 1,26 & $\mathrm{~b}$ & $207 \%$ \\
$\mathrm{~A} 2$ & 11,23 & $\mathrm{~b}$ & $397 \%$ & 1,52 & $\mathrm{bc}$ & 1,86 & $\mathrm{a}$ & $354 \%$ \\
$\mathrm{~A} 3$ & 14,21 & $\mathrm{a}$ & $529 \%$ & 1,63 & $\mathrm{bc}$ & 2,10 & $\mathrm{a}$ & $412 \%$ \\
$\mathrm{~B} 1$ & 7,70 & $\mathrm{c}$ & $241 \%$ & 2,07 & $\mathrm{a}$ & 1,35 & $\mathrm{~b}$ & $229 \%$ \\
$\mathrm{~B} 2$ & 11,13 & $\mathrm{~b}$ & $392 \%$ & 1,30 & $\mathrm{c}$ & 2,02 & $\mathrm{a}$ & $393 \%$ \\
$\mathrm{~B} 3$ & 13,58 & $\mathrm{ab}$ & $500 \%$ & 1,46 & $\mathrm{bc}$ & 2,13 & $\mathrm{a}$ & $419 \%$ \\
\hline Rerata FMA & 10,80 & & $378 \%$ & 1,63 & & 1,79 & & $337 \%$ \\
\hline
\end{tabular}

Keterangan (Remarks): Rerata sekolom diikuti huruf yang berbeda menunjukkan perbedaan yang nyata pada taraf kepercayaan 95\% berdasarkan uji Duncan (Mean values within each column followed by different letters indicate significant differences according to Duncan test at $95 \%$ confidence level) 


\section{Kolonisasi akar dan jumlah spora}

Interaksi antara perlakuan reformulasi inokulum FMA dan perlakuan dosis berpengaruh nyata terhadap kolonisasi akar dan jumlah spora. Perlakuan reformulasi inokulum FMA mampu meningkatkan kolonisasi akar dan jumlah spora FMA pada semai jati Muna jika dibandingkan dengan semai kontrol (Tabel 2).

Tabel(Table) 2. Pengaruh perlakuan reformulasi inokulum FMA dan dosis inokulum FMA terhadap kolonisasi akar (\%) dan jumlah spora pada semai jati Muna (The effect of reformulation inoculum of AMF and dosages inoculum of AMF on the roots colonisation and the number of spora at Muna teak seedling)

\begin{tabular}{|c|c|c|c|c|}
\hline $\begin{array}{l}\text { Perlakuan reformulasi inokulum FMA } \\
\text { (Treatment of AMF inoculum reformulation) }\end{array}$ & \multicolumn{2}{|c|}{$\begin{array}{l}\text { Kolonisasi akar }(\%) \\
\text { (Roots colonisation) }\end{array}$} & \multicolumn{2}{|c|}{$\begin{array}{l}\text { Jumlah spora } \\
\text { (Number of spora) }\end{array}$} \\
\hline Kontrol (Tanpa inokulum FMA) & 35,55 & $\mathrm{~h}$ & 14 & $\mathrm{~g}$ \\
\hline A1D1 (G. etunicatum, dosis $10 \mathrm{~g}$ inokulum FMA) & 65,56 & d-g & 234 & $a b c$ \\
\hline A1D2 (G. etunicatum, dosis 15 g inokulum FMA) & 71,11 & $\mathrm{c}-\mathrm{g}$ & 323 & $\mathrm{ab}$ \\
\hline A1D3 (G. etunicatum, dosis $20 \mathrm{~g}$ inokulum FMA) & 52,22 & $\mathrm{~g}$ & 278 & $a b c$ \\
\hline $\begin{array}{l}\text { A2D1 (G. etunicatum dengan vermikompos } 30 \% \text {, dosis } \\
10 \text { g inokulum FMA) }\end{array}$ & 80,00 & a-e & 151 & b-e \\
\hline $\begin{array}{l}\text { A2D2 (G. etunicatum dengan vermikompos } 30 \% \text {, dosis } \\
15 \text { g inokulum FMA) }\end{array}$ & 71,18 & $\mathrm{c}-\mathrm{g}$ & 369 & a \\
\hline $\begin{array}{l}\text { A2D3 (G. etunicatum dengan vermikompos } 30 \% \text {, dosis } \\
20 \text { g inokulum FMA) }\end{array}$ & 84,44 & a-e & 199 & $a-d$ \\
\hline $\begin{array}{l}\text { A3D1 (G. etunicatum dengan vermikompos } 40 \% \text {, dosis } \\
10 \text { g inokulum FMA) }\end{array}$ & 97,78 & a & 294 & $a b c$ \\
\hline $\begin{array}{l}\text { A3D2 (G. etunicatum dengan vermikompos } 40 \% \text {, dosis } \\
15 \text { g inokulum FMA) }\end{array}$ & 76,56 & a-e & 139 & cde \\
\hline $\begin{array}{l}\text { A3D3 (G. etunicatum dengan vermikompos } 40 \% \text {, dosis } \\
20 \text { g inokulum FMA) }\end{array}$ & 74,44 & $b-f$ & 209 & $a b c$ \\
\hline B1D1 (Glomus sp., dosis $10 \mathrm{~g}$ inokulum FMA) & 81,11 & a-e & 238 & $a b c$ \\
\hline B1D2 (Glomus sp., dosis $15 \mathrm{~g}$ inokulum FMA) & 53,33 & fg & 299 & $a b c$ \\
\hline B1D3 (Glomus sp., dosis $20 \mathrm{~g}$ inokulum FMA) & 82,22 & a-e & 230 & $a b c$ \\
\hline $\begin{array}{l}\text { B2D1 (Glomus sp. dengan vermikompos } 30 \% \text {, dosis } 10 \mathrm{~g} \\
\text { inokulum FMA) }\end{array}$ & 87,78 & a-d & 77 & ef \\
\hline $\begin{array}{l}\text { B2D2 (Glomus sp. dengan vermikompos } 30 \% \text {, dosis } 15 \mathrm{~g} \\
\text { inokulum FMA) }\end{array}$ & 84,44 & a-e & 152 & $b-e$ \\
\hline $\begin{array}{l}\text { B2D3 (Glomus sp. dengan vermikompos } 30 \% \text {, dosis } 20 \mathrm{~g} \\
\text { inokulum FMA) }\end{array}$ & 83,33 & a-e & 60 & $\mathrm{f}$ \\
\hline $\begin{array}{l}\text { B3D1 (Glomus sp. dengan vermikompos } 40 \% \text {, dosis } 10 \mathrm{~g} \\
\text { inokulum FMA) }\end{array}$ & 64,45 & efg & 180 & a-d \\
\hline $\begin{array}{l}\text { B3D2 (Glomus sp. dengan vermikompos } 40 \% \text {, dosis } 15 \mathrm{~g} \\
\text { inokulum FMA) }\end{array}$ & 90,00 & $\mathrm{abc}$ & 86 & def \\
\hline $\begin{array}{l}\text { B3D3 (Glomus sp. dengan vermikompos } 40 \% \text {, dosis } 20 \mathrm{~g} \\
\text { inokulum FMA) }\end{array}$ & 95,55 & $a b$ & 154 & a-e \\
\hline
\end{tabular}

Keterangan (Remarks): Rerata sekolom diikuti huruf yang berbeda menunjukkan perbedaan yang nyata pada taraf kepercayaan 95\% berdasarkan uji Duncan (within each column, mean values followed by different letters indicate significant differences according to Duncan test at $95 \%$ confidence level) 

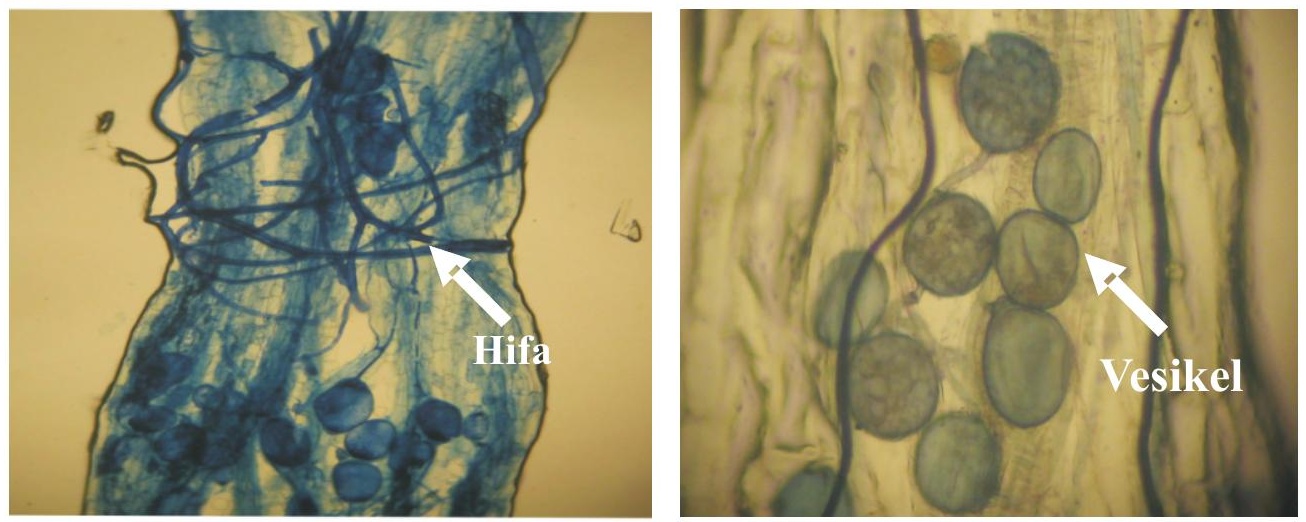

Gambar(Figure) 6. Hifa (a) dan vesikel (b) pada akar semai jati Muna pada umur 12 MST (Hypha and vesicle on the roots of Muna teak seedling 12 weeks after planting)

Kolonisasi akar pada semai yang diberi perlakuan reformulasi inokulum FMA memiliki rerata lebih dari 70\%. Perlakuan reformulasi inokulum A3 pada dosis $10 \mathrm{~g} /$ semai menghasilkan kolonisasi akar tertinggi yaitu sebesar $97,78 \%$ dan termasuk dalam kategori tingkat kolonisasi akar tertinggi (kelas 5) (Delvian et al., 2002), sedangkan perlakuan semai kontrol menunjukkan kolonisasi akar yang terendah yaitu sebesar $35,55 \%$ (Tabel 2). Kolonisasi akar berkorelasi nyata dengan peubah tinggi semai umur 12 MST ( $r=0,25 ; \mathrm{P}=0,0043)$, diameter semai umur 12 MST $(\mathrm{r}=0,34 ; \mathrm{P}=0,001)$, bobot kering akar $(\mathrm{r}=0,48$; $\mathrm{P}=0,0002)$ dan bobot kering semai $(\mathrm{r}=0,39 ; \mathrm{P}=0,0033)$.

Demikian pula dengan jumlah spora, terjadi peningkatan jumlah spora pada perlakuan reformulasi inokulum FMA. Rerata tertinggi terdapat pada perlakuan A2D2 (G. etunicatum dengan vermikompos 30\%, dosis $15 \mathrm{~g}$ inokulum FMA) yaitu sebesar 369 spora/30 g sampel tanah, sedangkan perlakuan kontrol menghasilkan jumlah spora terendah yaitu 14 spora $/ 30 \mathrm{~g}$ sampel tanah.

\section{B. Pembahasan}

Hasil penelitian menunjukkan bahwa semai jati Muna yang diinokulasi dengan perlakuan reformulasi inokulum FMA mulai memberikan pengaruhnya terhadap tinggi semai pada minggu ke- 6 dan diameter semai pada minggu ke-12. Kondisi ini sangat menguntungkan sebab respon pertumbuhan mulai nampak dalam waktu yang tidak begitu lama sehingga dapat mempersingkat waktu pemeliharaan di persemaian.

Perlakuan reformulasi inokulum FMA jenis G. etunicatum dengan vermikompos $40 \%$ (A3) dan Glomus sp. dengan vermikompos 40\% (B3) menghasilkan peningkatan tinggi dan diameter semai. Peningkatan ini berkaitan dengan kemampuan akar bermikoriza dalam menyerap unsur hara lebih luas (Alexopoulus et al., 1996; Brundrett et al., 1994) dan didukung oleh tersedianya faktor-faktor tumbuh secara optimal seperti unsur hara (vermikompos), air serta kondisi lingkungan yang cocok bagi pertumbuhan semai. Sebagaimana diketahui, FMA berfungsi dalam membantu penyerapan unsur hara baik yang tidak tersedia maupun yang tersedia, terutama bagi tanaman yang akarnya sudah tidak mampu menjangkau hara lagi. Sieverding (1991) menyatakan bahwa penyerapan hara oleh tanaman umumnya ditentukan oleh kemampuan akar dalam mengabsorbsi elemen hara dan difusi hara, sedangkan fungsi yang utama dari mikoriza adalah memperluas jangkauan penyerapan hara dan meningkatkan efisiensi penyerapan hara dari tanah. Peningkatan penyerapan hara terjadi karena hifa eksternal dari cendawan mikoriza yang berperan sebagai sistem perakaran, dapat menyediakan permukaan yang lebih efektif (lebih ekstensif dan lebih baik penyebarannya) dalam menyerap hara dari tanah dan kemudian dipindahkan ke akar inang. Hifa berperan sebagai jalan bebas hambatan untuk aliran fosfat melalui zona deplesi di sekeliling akar (Gunawan, 1993). Selanjutnya Smith dan Read (1997) menyatakan bahwa cendawan mikoriza mampu meningkatkan penyerapan hara utamanya fosfor dan hara lainnya seperti $\mathrm{Zn}$, $\mathrm{NH}_{4}, \mathrm{Cu}$ dari tanah dan lebih efisien dibanding tanaman yang tidak bermikoriza.

Jika membandingkan peningkatan pertumbuhan antara semai yang diinokulasi dengan perlakuan reformulasi inokulum FMA (A2,A3,B2 dan B3) dan semai yang diinokulasi FMA tanpa vermikompos 
(A1 dan B1) serta kontrol (Gambar 1), dapat diduga terjadi hubungan yang sinergis antara FMA dan vermikompos, kinerja FMA meningkat dengan adanya vermikompos. Perpaduan mikoriza dengan vermikompos dapat menyediakan berbagai unsur hara makro maupun mikro dan mempengaruhi pertumbuhan tanaman melalui pengaruhnya terhadap sifat-sifat fisik dan kimia tanah (Cavender, 2002). Pengaruh vermikompos terhadap tanah adalah meningkatkan porositas tanah, kemampuan mengikat air, kapasitas tukar kation, menstabilkan struktur tanah seperti mengurangi pemadatan tanah, meningkatkan infiltrasi, meningkatkan $\mathrm{pH}$ pada tanah masam dan menurunkan pengaruh logam-logam berat (Johnson dan Pfleger, 1992; Samosir, 1994). Porositas dan struktur tanah yang cenderung membaik akibat penambahan vermikompos diduga menyebabkan membaiknya perkembangan FMA pada areal perakaran semai.

Pada dasarnya tanaman harus memperoleh hara mineral yang cukup dari lingkungannya sebagai material pokok untuk semua reaksi biokimia yang kompleks bagi sel hidup dan pertumbuhan tanaman. Faktor-faktor lingkungan yang optimal seperti unsur hara, air, dan cahaya yang cukup akan meningkatkan proses fotosintesis yang mengakibatkan akumulasi bahan-bahan fotosintat yang akan digunakan untuk proses pertumbuhan. Peningkatan bobot kering semai tertinggi pada perlakuan inokulum A3 dan B3 berturut-turut sebesar 529\% dan 500\% dibanding kontrol (Tabel 1) sebagai akibat dari proses metabolisme yang berlangsung optimal, diduga karena adanya inokulasi FMA dan penambahan vermikompos yang menciptakan kondisi yang lebih baik untuk pertumbuhan semai jati. Penyerapan hara dan air yang cukup menjadikan proses fotosintesis berlangsung dengan optimal. Hal ini mengakibatkan terjadinya peningkatan akumulasi fotosintat yang kemudian ditransfer ke titik-titik tumbuh sehingga produktivitas dan perkembangan sel-sel jaringan berlangsung dengan cepat. Dari penelitian yang dilakukan oleh Turjaman et al. (2004) diketahui bahwa respon pertumbuhan semai jati terhadap inokulasi mikoriza arbuskula memberikan pengaruh yang sangat nyata pada bobot kering total tanaman mencapai 2 sampai 8 kali lebih baik dibanding kontrol.

Perlakuan reformulasi inokulum FMA mempengaruhi partisi bobot kering antara pucuk dan akar. Semai yang diinokulasi dengan reformulasi inokulum FMA berkisar dari 1,20 sampai 2,07 (cenderung seimbang). Nisbah pucuk akar adalah perbandingan antara bagian tanaman yang berfotosintesis dan bagian tanaman yang menyerap air dan hara mineral. Nisbah yang relatif seimbang menunjukkan bahwa fotosintat tidak hanya digunakan untuk pertumbuhan bagian atas pucuk akan tetapi juga dialokasikan untuk pertumbuhan dan perkembangan akar. Diduga bahwa aktivitas FMA pada areal perakaran merangsang alokasi fotosintat untuk ditransfer kebagian akar dan tentu saja dengan diimbangi dengan penyerapan unsur hara yang cukup oleh FMA untuk disalurkan ke bagian atas tanaman. Kondisi ini memberikan pengaruh yang positif karena perakaran semai yang baik dapat meningkatkan kemampuan semai untuk dapat tumbuh dan berkembang dengan normal di lapangan.

Perlakuan reformulasi inokulum A3 dan B3 juga menghasilkan bobot kering akar terinfeksi tertinggi dengan peningkatan berturut-turut $412 \%$ dan $419 \%$ dibanding kontrol (Tabel 1). Kondisi ini mengindikasikan bahwa FMA mampu meningkatkan penyerapan unsur hara dari tanah yang selanjutnya ditranslokasikan ke akar inangnya. Dengan demikian terjadi peningkatan translokasi hara ke bagian atas semai sebagai bahan baku fotosintesis mengakibatkan peningkatan penggunaan asimilat dalam pucuk serta peningkatan suplai fotosintat dari daun ke akar. Sebagian dari hasil fotosintat akan dipakai untuk perkembangan akar, sumber energi untuk serapan unsur hara dan sebagian lagi digunakan oleh FMA. Perkembangan akar yang lebih baik kemungkinan juga disebabkan oleh adanya hormon perangsang tumbuh yang dihasilkan oleh FMA (Marschner, 1992) dan atau dari vermikompos (Nuryati, 2004). Perkembangan akar yang baik mengakibatkan banyaknya akar-akar yang terbentuk sehingga semakin besar peluang dari FMA untuk menginfeksi akar tersebut. Dalam hal ini semakin banyak areal-areal yang dapat dikoloni untuk mendapatkan eksudat akar. Dimana proses kolonisasi kebanyakan terjadi pada akarakar muda karena permeabilitas membran yang tinggi (Sieverding, 1991). Penelitian Bucking dan Shachar-Hill (2005) mendapatkan bahwa serapan P oleh miselium ekstraradikal dan translokasinya ke akar bermikoriza dan distribusi $\mathrm{P}$ dalam tubuh cendawan akan semakin meningkat sejalan dengan peningkatan ketersediaan karbohidrat. Suplai sukrosa akan menurunkan pembentukan polifosfat tetapi meningkatkan pembentukan fosfolipida dan ikatan-ikatan P yang berkaitan dengan pertumbuhan lainnya sekaligus meningkatkan taraf $\mathrm{P}$ sitoplasmik dalam miselium intraradikal dan taraf $\mathrm{P}$ sitoplasmik dalam kortek akar. Penelitian ini telah membuktikan bahwa serapan $\mathrm{P}$ oleh cendawan dan perpindahannya ke tanaman inang juga dirangsang oleh perpindahan karbon dari tanaman ke cendawan. 
Pada perlakuan akar semai kontrol juga terinfeksi oleh FMA dan terdapat spora. Hal ini diduga karena pada media tanah semai jati juga terdapat FMA alam. Berdasarkan data terlihat bahwa kemampuan kompetitif jenis FMA yang diinokulasikan lebih besar dibanding jenis FMA alam. Jika dihubungkan dengan peningkatan pertumbuhan maka FMA pada perlakuan kontrol tidak memberikan kontribusi yang berarti pada semai jati Muna, terlihat dari peningkatan pertumbuhan yang relatif tidak terlalu besar. Menurut Bagyaraj (1991), kemampuan cendawan untuk berhasil berkompetisi dengan cendawan lain tergantung pada keagresifan (aggressiveness) cendawan tersebut.

Perkembangan FMA yang relatif baik pada akar semai jati Muna juga diduga karena pengaruh tingkat ketersediaan $\mathrm{P}$ yang rendah pada media tanah yang digunakan. Hasil analisis tanah menunjukkan bahwa kandungan $\mathrm{N}$ dan $\mathrm{P}$ adalah sangat rendah dan rendah dengan kondisi $\mathrm{pH}$ yang agak masam (Lampiran). Jumlah P tidak tersedia sebesar 30,60 ppm dan P tersedia adalah 4,90 ppm dengan kategori sangat rendah. Kondisi ini menunjukkan perlunya keterlibatan FMA dalam membantu penyediaan hara dari tidak tersedia menjadi tersedia. Peningkatan pelepasan asam-asam organik dan aktivitas asam fosfatase di rhizosfir dapat dikatakan berguna untuk meningkatkan serapan $\mathrm{P}$ dari sumber-sumber $\mathrm{P}$ anorganik dan organik (Gahoonia dan Nielsen, 2004). Data ini memberikan informasi bahwa semai jati efektif bersimbiosis dengan FMA pada kondisi agak masam dan P terbatas. Menurut Smith dan Read (1997), bahwa kolonisasi akar oleh FMA dan sporulasi yang maksimum terjadi pada lahan-lahan dengan kesuburan tanah yang rendah. Kandungan $\mathrm{P}$ total yang termasuk kategori rendah dan $\mathrm{P}$ tersedia sangat rendah serta $\mathrm{pH}$ yang agak masam memungkinkan pembentukan simbiosis FMA dengan semai jati berlangsung dengan baik.

Peningkatan kolonisasi akar cenderung berpengaruh positif terhadap pertumbuhan semai jati Muna. Kondisi ini mengindikasikan bahwa semakin banyaknya hifa-hifa yang membantu penyerapan dan penyediaan unsur hara untuk pertumbuhan jati. Pada media tanah terjadi interaksi yang lebih kompleks antara tanaman, tanah dan mikroorganisme yang terdapat didalamnya. Hal menarik yang didapatkan adalah respon kolonisasi akar dan jumlah spora pada media tanah cenderung membaik. Diduga bahwa vermikompos secara tidak langsung juga mempengaruhi pertumbuhan tanaman dengan perbaikan struktur fisik dan kimia tanah (Cavender 2002), sehingga merangsang peningkatan populasi mikroorganisme tanah yang menguntungkan seperti bakteri (Betty et al., 2004) dan mempengaruhi aktivitas enzim-enzim tanah (Marinari et al., 1999). Menurut Paulitz dan Liderman (1991) menyatakan bahwa tingkat kolonisasi akar oleh FMA dan pengaruhnya dalam simbiosis adalah beragam tergantung pada total interaksi antara inang, FMA dan lingkungannya. Pada umumnya interaksi antara FMA dan mikroorganisme tanah lainnya adalah positif dan dapat meningkatkan keefektivan dari FMA. Hal ini didukung oleh Wilarso (2000) yang menyatakan bahwa perkembangan tanaman dapat diperbaiki dengan menggunakan kombinasi antara FMA dan mikroorganisme tanah yang lain didalam rhizosfir. FMA merupakan salah satu komponen yang sangat penting dalam ekosistem dan regulasi pembentukan serta fungsinya dipengaruhi oleh mikroorganisme tanah. FMA berdampak pada perbaikan pertumbuhan tanaman.

\section{KESIMPULAN DAN SARAN}

\section{A. Kesimpulan}

Perlakuan reformulasi inokulum FMA mampu meningkatkan pertumbuhan semai jati Muna. Perlakuan inokulum G. etunicatum dengan vermikompos 40\% (A3) dan Glomus sp. dengan vermikompos $40 \%$ (B3) menghasilkan peningkatan bobot kering semai berturut-turut sebesar $529 \%$ dan $500 \%$ dibandingkan dengan kontrol, dan pemberian dosis reformulasi inokulum FMA $15 \mathrm{~g} / \mathrm{semai}$ merupakan dosis optimum untuk dapat meningkatkan tinggi dan diameter semai jati Muna. Peubah kolonisasi akar cenderung berkorelasi positif dengan peubah pertumbuhan semai jati Muna.

\section{B. Saran}

Aplikasi reformulasi inokulum FMA sebaiknya digunakan pada saat baru panen (inokulum segar) sehingga dapat menghasilkan respon pertumbuhan dan kolonisasi akar terbaik. 


\section{UCAPAN TERIMA KASIH}

Ucapan terima kasih kepada Dr.Ir. Irdika Mansur, M.For.Sc, Dr.Ir. Sri Wilarso Budi, MS., Dr.Ir. Dedy Duryadi Solihin, DEA, Dr.Ir. Iskandar Z. Siregar, M.For.Sc. dan Ir. Abimayu D. Nusantara, MP. yang telah memberikan petunjuk dan saran perbaikan dalam melakukan penelitian ini.

\section{DAFTAR PUSTAKA}

Alexopoulos, C.J., Mims, C.W., Blackwell, M. 1996. Introductory Mycology. Fourth Edition. John Wiley $\&$ Sons Inc. United States of America.

Anonim. 2005. Hasil seleksi pohon induk jati Muna perbanyakan bibit melalui kultur jaringan. Makalah disampaikan dalam Semiloka Kehutanan: Pemanfaatan lahan-lahan kehutanan yang terbuka karena "Penebangan Tanpa Rencana" sebagai sumber pendapatan baru bagi masyarakat lingkungan hutan ataupun masyarakat pada umumnya. Kerjasama antara Forum Kerjasama Delapan Perguruan Tinggi (FK8PT) dengan LPIU FK8PT Universitas Haluoleo. Kendari.

Bagyaraj, D.J. 1991. Ecology of Vesicular-arbuscular Mycorrhizae. in. Arora DK, Rai B, Mukerji KG, Knudsen GR. [editors]. Handbook of applied mycology. Soil and plants. Marcell Dekker Inc. New York. pp. 3-34.

Betty, N.F., Mieke, R.S., Reginawanti, H. 2004. Aplikasi pupuk organik (kascing dan ekstrak cacing) serta cendawan mikoriza arbuskula terhadap populasi mikroba di rizosfir, kolonisasi mikoriza, pertumbuhan dan hasil tanaman jagung manis pada ultisols. Di dalam: Simarmata T., Dedeh HA., Yuyun S., Reginawanti H., Aziz A., Kalay AM. [editor]. Teknologi produksi dan pemanfaatan inokulan endo-ektomikoriza untuk pertanian, perkebunan dan kehutanan; Kerjasama AMI dan UNPAD Bandung. Bandung. hlm 32-40.

Brundrett, M., Bougher, N., Dell B., Grove, T., Malajczuk, N. 1994. Working with mycorrhiza in forestry and agriculture. International Mycorrhiza Workshop in Kaiping. Cina.

Brundrett, M. 2004. Diversity and classification of mycorrhiza associations. Journal of Biology. Rev.79: 473-495.

Bucking, H., Shachar-Hill, Y. 2005. Phosphate uptake, transport and transfer by the arbuscular mycorrhiza fungus Glomus intraradices is stimulated by increased carbohydrate availability. New Phytologist 165(3):899-912.

Cavender, N.D., Atiyeh, R.M., Knee, M. 2002. Vermicompost stimulates mycorrhiza colonization of root of Sorghum bicolor at the expense of plant gowth. Pedobiologia 47: 85-89.

Delvian, Maryanti D., Irmayanti. 2002. Materi pelatihan teknik dasar pengenalan dan pengembangan serta pemanfaatan cendawan mikoriza arbuskula. Laboratorium Bioteknologi Hutan dan Lingkungan. Pusat Penelitian Bioteknologi IPB. Bogor.

Gahoonia, T.S., Nielsen, N.E. 2004. Root traits as tools for creating phosphorus efficient crop varieties. Plant and Soil 260(1-2):47-57.

Gunawan, A.W. 1993. Mikoriza Arbuskula. Pusat Antar Universitas Ilmu Hayat. Institut Pertanian Bogor. Bogor.

Hardjowigeno, S. 1995. Ilmu Tanah. Penerbit Akademika Pressindo. Jakarta.

Husna. 2005. Pemanfaatan pupuk hayati mikoriza dalam rehabilitasi hutan jati di Sulawesi Tenggara. Makalah disampaikan dalam Semiloka Kehutanan : Pemanfaatan lahan-lahan kehutanan yang terbuka karena "Penebangan Tanpa Rencana" sebagai sumber pendapatan baru bagai masyarakat lingkungan hutan ataupun masyarakat pada umumnya. Kerjasama antara Formum Kerjasama Delapan Perguruan Tinggi (FK8PT) dengan LPIU FK8PT Universitas Haluoleo. Kendari. 
Johnson, N.C., Pfleger, F.L. 1992. Vesicular-arbuscular mycorrhiza and cultural stresses; In. Bethlenfalvay GJ, Linderman RG. [Editors]. Mycorrhiza in sustainable agiculture. American Crop and Soil Science Society ASA Specl. USA. Publ.54:71-99.

Marschner, H. 1992. Nutrient dynamics at the soil-root interface (Rhizosphere); In. Read DJ, Lewis DH, Fitter AH, Alexander IJ. [Editors]. Mycorrhiza in ecosystems. Cambridge Univ. Press. Singapore.

Marinari, S., Masciandaro, G., Ceccanti, B., Gego, S. 1999. Influence of organic and mineral fertilizers on soil biological and physical properties. Bioresource of Technology 72:9-17.

Mattjik, A.A., Sumertajaya, I.M. 2002. Perancangan Percobaan dengan Aplikasi SAS dan Minitab. Jilid I. IPB PRESS. Bogor.

Nuryati, S. 2004. Memanfaatkan cacing tanah untuk hasilkan pupuk organik. Http.// www.beritabumi.or.id/berita 3.php?id berita $=29$ (15 Februari 2005).

Paulitz, T.C., Linderman, R.G. 1991. Mycorrhiza interaction with soil organism. In Arora DK, Rai B, Mukerji KG, Knudsen GR. [editors]. Handbook of applied mycology. Soil and plants. Marcell Dekker Inc. New York. pp. 77-129.

Rajapakse, S., Miller, J.C.J. 1992. Methods for studying vesicular-arbuscular mycorrhiza root colonization and related root physical properties. Microbiology. 24:301-316.

Rizain, A.W. 1999. Pengaruh tipe penyerbukan terhadap produksi benih dan peran perlakuan invigorasi terhadap peningkatan perkecambahan benih jati (Tectona grandis L. f.). Tesis. Progam Pascasarjana IPB. Bogor.

Samosir, S.S.R. 1994. Kimia Tanah. Fakultas Pertanian UNHAS. Ujung Pandang.

Sieverding, E. 1991. Vesicular-arbuscular mycorrhiza management in tropical agosystem. Eschborne. Deutsche Gesellschaft fur Technische Zusammenarbeit (GTZ) GmbH.

Smith, S.E., Read, D.J. 1997. Mycorrhiza Symbiosis. Second Eds. Academic Press Harcourt Brace and Company Publ. San Diego California.

Turjaman, M., Sitepu, I.R., Irianto, R.S.B., Santoso, E. 2004. Penggunaan cendawan mikoriza arbuskula Glomus manihotis dan Glomus aggregatum sebagai pemacu pertumbuhan semai jati (Tectona grandis) asal Jatirogo di pesemaian; di dalam: Simarmata T., Dedeh HA., Yuyun S., Reginawanti H., AzizA., Kalay AM. [editor]. Teknologi produksi dan pemanfaatan inokulan endo-ektomikoriza untuk pertanian, perkebunan dan kehutanan; Kerjasama AMI dan UNPAD Bandung. Bandung. hlm 121-135.

Wilarso, S.B. 2000. Interaksi positif antara cendawan mikoriza arbuskula dengan mikroorganisme tanah. Di dalam: Setiadi Y., Hadi S., Santoso E., Turjaman M., Irianto RSB., Prematuri R., Maryanti D., Widopratiwi R. [Editor]. Prosiding. Seminar Nasional I. Penerbit Pusat penelitian dan Pengembangan Hutan dan Konservasi Alam, Badan Penelitian dan Pengembangan Kehutanan dan Perkebunan, Departemen Kehutanan dan Perkebunan. Bogor. 


\section{LAMPIRAN}

Tabel(Table) 1. Sifat tanah lapisan atas Latosol" pada media semai jati Muna (Soil characteristics of Latosol top-soil on the media of Muna teak seedling)

\begin{tabular}{|c|c|c|}
\hline $\begin{array}{c}\text { Sifat tanah } \\
\text { (Soil characteristics) }\end{array}$ & Nilai (Value) & Kelas $^{* *}$ (Class) \\
\hline C-org $(\%)$ & 0,64 & Sangat rendah (very low) \\
\hline $\mathrm{N}$ total $(\%)$ & 0,06 & Sangat rendah (very low) \\
\hline $\mathrm{C} / \mathrm{N}$ & 10,67 & Rendah (low) \\
\hline $\mathrm{P} \mathrm{HCl} 25 \%(\mathrm{ppm})$ & 30,60 & Sedang (medium) \\
\hline P Bray $1(\mathrm{ppm})$ & 4,90 & Sangat rendah (very low) \\
\hline$N \mathrm{KCl}, \mathrm{Al}(\mathrm{me} / 100 \mathrm{~g})$ & 0,12 & \\
\hline $\mathrm{KCl}, \mathrm{H}(\mathrm{me} / 100 \mathrm{~g})$ & 0,20 & \\
\hline $\begin{array}{l}0.05 N \mathrm{HCl}(\mathrm{ppm}) \\
\mathrm{Fe} \\
\mathrm{Cu} \\
\mathrm{Zn} \\
\mathrm{Mn}\end{array}$ & $\begin{array}{c}10,80 \\
12,56 \\
15,52 \\
185,56 \\
\end{array}$ & \\
\hline $\begin{array}{l}\mathrm{NNH}_{4} \mathrm{Oac} \mathrm{pH} 7.0 \\
\mathrm{KTK}(\mathrm{me} / 100 \text { gr) } \\
\text { Susunan Kation : } \\
\mathrm{K}(\mathrm{me} / 100 \mathrm{gr}) \\
\mathrm{Na}(\mathrm{me} / 100 \mathrm{gr}) \\
\mathrm{Mg}(\mathrm{me} / 100 \mathrm{gr}) \\
\mathrm{Ca}(\mathrm{me} / 100 \mathrm{gr}) \\
\text { Kejenuhan basa }(\%)\end{array}$ & $\begin{array}{c}0,30 \\
0,38 \\
2,52 \\
10,40 \\
100,00\end{array}$ & $\begin{array}{l}\text { Rendah (low) } \\
\text { Sedang (medium) } \\
\text { sedang (medium) } \\
\text { Tinggi (high) } \\
\text { sedang (medium) } \\
\text { sangat tinggi (very high) }\end{array}$ \\
\hline
\end{tabular}

Keterangan(Remarks) : Analisis tanah dilakukan oleh Laboratorium Departemen Ilmu Tanah dan Sumberdaya Lahan Fakultas Pertanian IPB; *) Tanah latosol pada daerah Cibanteng Bogor, **) Menurut kriteria Pusat Penelitian Tanah Bogor (Hardjowigeno, 1995) 